\title{
LEARNING TO USE STATISTICS IN RESEARCH: A CASE STUDY OF LEARNING IN A UNIVERSITY- BASED STATISTICAL CONSULTING CENTRE
}

\author{
MICHELLE K. MCGINN \\ Faculty of Education, Brock University \\ mcginn@brocku.ca
}

\begin{abstract}
This paper presents a qualitative case study of statistical practice in a universitybased statistical consulting centre. Naturally occurring conversations and activities in the consulting sessions provided opportunities to observe questions, problems, and decisions related to selecting, using, and reporting statistics and statistical techniques in research. The consulting sessions provided simultaneous opportunities for consultants and clients to learn about using statistics in research. Consistent with contemporary theories that emphasize social dimensions of learning, major themes relate to (a) types of clients and consulting interactions, (b) disciplinary and statistical expertise, and (c) the role of material objects and representations. Evidence shows that consultants and clients learned during the consulting sessions and that the statistical consulting centre contributed positively to teaching and research at the university.
\end{abstract}

Keywords: Statistics education research; Social learning; Qualitative case study; Ethnostatistics

\section{INTRODUCTION}

Statistical practice involves contingent procedures and artful decision making, not the rote application of accepted formulas as is sometimes assumed. Drawing upon a foundation in ethnostatistics (Gephart, 1988, 2006) and social learning theories (Salomon \& Perkins, 1998), this paper presents a qualitative case study (Merriam, 2009; Stake, 2005) of statistical practice in a university-based statistical consulting centre. Naturally occurring conversations and activities in the consulting sessions provided opportunities to observe questions, problems, and decisions related to selecting, using, and reporting statistics and statistical techniques in research. The purpose of this paper is to document learning opportunities for consultants and clients during statistical consulting sessions as a means to assess the role of a statistical consulting centre in the research and teaching functions of a university.

\subsection{STATISTICS EDUCATION AND STATISTICAL CONSULTING}

Learning about statistical consulting is recognized as an important component of education programs for professional statisticians. Many universities provide statistical consulting courses or modules to support the development of their graduates (Cabrera \& McDougall, 2002; Jersky, 2002; Jeske, Lesch, \& Deng, 2007; Taplin, 2007). For example, Särkkä and Sagitov (2008) identify four major aims for their new master's

Statistics Education Research Journal, 9(2), 35-49, http://www.stat.auckland.ac.nz/serj

(C) International Association for Statistical Education (IASE/ISI), November, 2010 
course on statistical consulting: (a) learning to discuss statistical issues with researchers who are not statistics specialists, (b) formulating disciplinary problems in statistical terms, (c) choosing appropriate statistical models and methods, and (d) writing and presenting reports.

Statistical consulting requires statistical, computational, scientific, and communication skills (Cabrera \& McDougall, 2002). It is clear that these are important skills for future statisticians and relevant components of statistics degree programs. These are also skills that are needed by researchers across multiple fields who use statistics to advance disciplinary knowledge, so there is a potential role for statistical consulting in other disciplinary programs beyond statistics. Statistical consulting is "a forum for interaction between statistician and researcher and therefore should be a fertile ground for learning on both sides” (Belli, 2001, p. 326). In the social setting of a consulting session, statisticians and researchers can learn how statistics are produced, used, and communicated as part of the cycle of generating and disseminating research knowledge.

\subsection{STATISTICS IN ACTION}

Statistical analysis and statistical thinking involve much more than manipulating numbers using set formulas (Reid \& Petocz, 2002; Wild \& Pfannkuch, 1999). Producing, composing, applying, using, understanding, or communicating statistics requires tacit knowledge, heuristics, communication skills, and a facility to capitalize on the social situation. Gephart (1988) coined the label "ethnostatistics” to refer to community-specific approaches that shape the use of statistical methods in research. The field of ethnostatistics involves the "empirical study of how professional scholars construct and use statistics and numerals in scholarly research” (Gephart, 2006, p. 417). Gephart (1988, 2006) delineated three general areas of scholarship within ethnostatistics: (a) ethnographic studies of groups who produce statistics (e.g., Latour \& Woolgar, 1986; Lynch, 1985), (b) analyses of the technical and practical assumptions involved in producing statistics (e.g., Cohen, 1994; Lieberson, 1985), and (c) analyses of the use of statistics as rhetorical or persuasive devices in research publications (e.g., McCloskey, 1985; Roth, Bowen, \& McGinn, 1999). All three areas of scholarship reveal that contingent practices and artful decision making are ubiquitous in statistical analysis.

Findings drawn from the field of ethnostatistics stand in stark contrast to mainstream beliefs about the perceived objectivity and precision of statistical methods. Many novice statistics users seem to believe that statistical methods of data analysis proceed in strictly methodical fashion whereby the researcher uses a pattern recognition strategy to select data analysis methods that match the research question and accumulated data. This myth suggests that once the researcher has selected the "correct" strategy, it is a simple matter of following the corresponding steps to complete the analysis, and the results of this analysis are then slotted into a research report template. Experienced statistics users know that researchers are not constrained in this way, yet the myth persists, leading statistics educators to question how to support students to develop more accurate and robust conceptions of statistics (Reid \& Petocz, 2002).

\subsection{SOCIAL LEARNING THEORIES}

Increasingly, researchers, theorists, and practitioners emphasize learning as a social phenomenon (Lave \& Wenger, 1991; McGinn, 2009; Packer \& Goicoechea, 2000; Salomon \& Perkins, 1998). People interact and learn in social settings, and part of what they learn is social content. Even when individuals work or study independently, they 
interact with books and tools that are socially located. To understand learning, it is therefore necessary to consider the social milieu for that learning, which includes considering who learners are, whom they interact with, and what learners and others do. Social learning theories also draw attention to the relationship between the social milieu where learning is developed and the social milieu where learners are expected to apply that learning. This focus leads some scholars and practitioners to advocate for "authentic learning" where the setting for initial learning is designed to resemble the settings for desired application (Herrington \& Herrington, 2006; Rule, 2006).

Salomon and Perkins (1998) provide a comprehensive review of a multitude of theoretical and empirical investigations of the ways that learning is social. For this study, I adopt their typology to describe learning opportunities for statistical consultants and clients. Specifically, I consider the ways that statistical consulting sessions provided opportunities for five forms of social learning: (a) active social mediation of individual learning, where the focus was on what and how an individual learned through interactions with another individual or team (e.g., what a client learned from a consultant's intervention); (b) social mediation as participatory knowledge construction, where the focus was on the development or engagement of a group or community (e.g., how a client and consultant discovered an appropriate statistical technique together); (c) social mediation by cultural scaffolding, where the focus included cultural artifacts (e.g., tools, language) that contributed to learning (e.g., a consultant looked up a formula in a statistics textbook); (d) the social entity as a learning system (e.g., how a consulting team learned over time to improve service for clients); and (e) learning to be a social learner (e.g., how a client learned to frame questions to solicit information in a usable form from a consultant).

\section{RESEARCH METHODS}

This is a qualitative case study (Merriam, 2009; Stake, 2005) of learning in a statistical consulting centre housed in the statistics department of a mid-sized, researchfocused university. The case is limited to consulting sessions involving university-based clients. Qualitative case study research is sensitive to the social setting and is therefore an appropriate methodological approach to investigate social learning (McGinn, 2009).

\subsection{THE UNIVERSITY-BASED STATISTICAL CONSULTING CENTRE}

Established in 1980, the primary goal for the centre was to educate statistics postgraduate students and expose them to real applications of statistical knowledge. The centre was intended to (a) improve education in the statistics department, (b) promote links between the department and the rest of the university, and (c) provide statistical advice to individuals engaged in data-based projects. These objectives are similar to those for other university-based statistical consulting services (Belli, 2001; Godino, Batanero, \& Jaimez, 2001; Jersky, 2002; Jeske et al., 2007). The centre provided consulting services to clients from within and beyond the university.

The centre director (Ian) had a master's degree in statistics and several years consulting experience. Ian took primary responsibility for consulting with clients and supporting postgraduate students who served a two-term internship with the consulting centre as part of their degree requirements. In the first term of their internship, student consultants enrolled in a non-credit required course that involved observing at least three to five hours of consultations and participating in a series of class meetings. Class meetings were devoted to discussing issues raised in statistical consulting sessions and 
studying a handbook on human factors in statistical consultation (Boen \& Zahn, 1982). In the second term, student consultants enrolled in a second non-credit course that involved guided and independent consultations with supervision from Ian. The internships provided opportunities for students to apply their statistical knowledge to actual research projects and to practice negotiating with clients, writing invoices, preparing bids, and addressing other non-statistical issues that are important for consultants.

Due to contractual arrangements (including privacy agreements), student consultants were seldom involved with non-university clients. As a result of these privacy agreements and the exclusion of student consultants, only university-based clients were involved in the present research. The majority of university-based consultations were completed in a single visit of less than one hour. Consultants worked with university-based clients to clarify goals and develop analysis plans, but these clients did the actual work. This contrasts with the consulting approach that predominated with non-university clients who hired consultants to perform analyses on their behalf.

\subsection{DATA COLLECTION AND ANALYSIS}

Following ethics clearance from the host university, I documented statistical consulting sessions for four months (one academic term). Ian, one or more student consultants, and university-based clients seeking statistical advice attended each session. (Clients and student consultants are protected through pseudonyms and some disguised details.) During the sessions, I took fieldnotes and participated in the discussions as appropriate. After the sessions, I expanded these fieldnotes to provide detailed case records for each observed session (Emerson, Fretz, \& Shaw, 2001; Patton, 1980).

I used open coding and constant comparison to analyze the data (Charmaz, 2006; Dye, Schatz, Rosenburg, \& Coleman, 2000). I read and re-read my fieldnotes and case records, marking significant events and themes. Through this process, I identified key themes that I then used to code the entire data corpus. After arriving at a set of key themes, I sought confirmation of my interpretations from two sources.

First, I compared my claims to the statistical consulting handbook that was required reading for the student consultants (Boen \& Zahn, 1982). I read the book from cover to cover, noting how the text related to the themes and examples from my fieldwork. The text is a well-respected handbook on "human" factors in statistical consulting that is recognized as a "classic" (Cabrera \& McDougall, 2002, p. 13). This review provided a partial check on the representativeness of these consulting sessions. For added resources, I also consulted other texts on statistical consulting (Cabrera \& McDougall; Derr, 2000; Hand \& Everitt, 2008; Rustagi \& Wolfe, 1982). These comparisons revealed a close match between interpretations drawn from fieldwork and the topics addressed in statistical consulting texts.

Second, Ian reviewed and approved a written report of the analyses. Ian's endorsement of my interpretations served as a "member check" (Lincoln \& Guba, 1985), demonstrating that the descriptions of the consulting sessions held for an "insider," that is, for the person who ran the service. At the same time, securing Ian's approval for this analysis complied with the standard consulting agreement whereby clients were expected to acknowledge assistance they received from the centre and ensure the centre approved their interpretations.

As Creswell and Miller (2000) argue, it is critically important in qualitative research to consider credibility from the perspectives of the researcher, the research participants, and the target audience for the research. These two review strategies provided increased 
assurance that Ian and other statisticians and statistics educators deemed the key themes presented here as credible and useful.

\section{STATISTICS LEARNING AND PRACTICE IN A UNIVERSITY-BASED STATISTICAL CONSULTING CENTRE}

Through my analyses, I identified three key themes related to (a) types of clients and consulting interactions, (b) disciplinary and statistical expertise, and (c) the role of material objects and representations. As I elaborate in each of the following sections, Salomon and Perkins' (1998) typology of social learning contributed to my understanding of these themes. I illustrate the key themes using examples from consulting sessions with three selected clients: Aaron (a pest management master's student), Rhonda (a plant biology doctoral student), and Tom (a kinesiology professor). I purposefully selected these three consulting sessions to demonstrate the diversity and range of client interactions observed over the four-month period.

\subsection{TYPES OF CLIENTS AND CONSULTING INTERACTIONS}

Consistent with the published literature (Boen \& Zahn, 1982; Hand \& Everitt, 2008; Rustagi \& Wolfe, 1982), I observed distinct differences in the ways that clients presented themselves and their statistical questions. For example, Rhonda commented several times about her lack of knowledge in statistics. She joked that the presence of extra observers (the student consultants and me) meant there would be many witnesses to her difficulties in statistics. Her consulting session seemed to be framed as a counselling session to prepare for an upcoming meeting with her supervisory committee where she would need to report her progress and defend her analyses. Rhonda treated the student consultants and me as observers, and focused her attention on Ian. Her interactions were almost all directed toward Ian, and only occasionally involved a student consultant or me.

Rhonda fit the profile of a "dependent" client: She seemed to require constant reassurance and support (Boen \& Zahn, 1982) and she exhibited statistics anxiety (Onwuegbuzie, 2000). In response, Ian offered mini-lessons on statistical topics such as degrees of freedom and correlation coefficients, he wrote procedure statements on pieces of paper that Rhonda was able to take away with her, and he offered to help Rhonda on an ongoing basis via email. Ian also spent considerable time reviewing what Rhonda had accomplished since the previous meeting and checking to ensure that she had understood and followed through on his previous recommendations. Rhonda listened attentively, took notes, and asked questions, but seldom offered her insights. These interactions represented active social mediation of individual learning (Salomon \& Perkins, 1998). Ian served as an external social agent who facilitated Rhonda's individual learning processes.

The consultation with Rhonda provided a very different environment than the consultation with Aaron who arrived at his session with one page of typed notes describing his research design and "Analysis to Date (and Problems)" (a heading that appeared mid-way through his prepared notes). His presentation was quite formal, almost like a conference presentation or thesis defence. He presented his work, referring to his notes and a set of "props" (cultural scaffolds) that included (a) a small plastic cage with samples of his target species and infesting parasites, (b) sample pages of statistical output, and (c) a handbook for his statistical software. Ian, Diane (the attending student consultant), and I were placed in the role of audience members for his presentation.

Aaron's presentation was highly interactive as he described and defended his research. For example, Diane asked whether it would be possible for the parasites to 
reproduce in the cage, thereby introducing a confound that would mean his stated sample size was inaccurate. Aaron acknowledged this as a good question, and then explained the parasite's reproduction cycle and how it was a biological impossibility for reproduction to occur in the cage. Aaron acted as an expert on his research topic, as would be expected from anyone formally presenting research.

Although Aaron came to the statistical consulting session seeking assistance with the use of statistics in his research, he was not a novice dependent on expert assistance. Furthermore, he seemed equally interested in the questions and suggestions from all participants in the consulting session (Ian, Diane, and me), revealing a less hierarchical flow of information than in Rhonda's session. In this way, Aaron's sessions exemplified participatory knowledge construction (Salomon \& Perkins, 1998) as he and the consultants collaboratively generated solutions to his design and analysis challenges. The session proceeded as a conversation among colleagues.

Tom presented as a third client type. He rushed in 15 minutes late, carrying only a pen and a blank piece of paper. He took charge of the meeting and quickly explained his question, sketching as he talked. Tom directed the discussion and looked to Ian for advice on one specific issue. In response to Tom's demeanour, Ian adopted the role of technician seeking a technical answer to Tom's question.

Initially, Tom seemed not to even notice the student consultant (Mirjana) or me. Tom finally looked at Mirjana when she broke into the discussion with a suggestion about a possible analysis. He did not, however, take the time to listen to her full explanation, instead he assumed she was suggesting the use of a particular technique involving vector sums, which he thought would work and he immediately concluded the session, leaving Mirjana to explain her suggestion to Ian after Tom's departure. Tom's emphasis was on securing the piece of information that would allow him to proceed with his work. Although Tom believed this information would come from Ian, it was actually Tom's (mis)interpretation of what Mirjana said that prompted his decision to proceed in a particular way. This is an example of active social mediation of individual learning (Salomon \& Perkins, 1998) with both Ian and Mirjana providing social mediation.

The three types of consultations affected the nature of the communication between consultants and clients. Ian seemed to be attuned to these differences and adapted his interaction styles appropriately (Derr, 2000; Platt, 1982) by drawing upon social content within the consulting sessions. Over time, the student consultants began to follow Ian's model, and sometimes debriefed with Ian about the interaction styles after a client left. The student consultants were learning skills to work together socially with clients (Salomon \& Perkins, 1998).

\subsection{DISCIPLINARY AND STATISTICAL EXPERTISE}

Using statistics in research requires statistical and disciplinary knowledge. The typical expectation is that statisticians hold statistical knowledge and researchers hold disciplinary knowledge, and that consulting sessions provide a space to bring the two together (Belli, 2001; Cabrera \& McDougall, 2002). Differences in the ways clients presented themselves and their statistical questions suggest that these roles were not so firmly established. There were evident distinctions in the extent to which expertise was distributed amongst the participants in each consulting session.

Tom's session focused predominantly on his disciplinary kinesiology expertise. He presented himself as an expert who needed one small piece of information from Ian to help him communicate his disciplinary understandings to other kinesiologists. Tom displayed little patience for Ian's statistics lessons or questions, and quickly pointed to his 
own sophistication in statistics and programming. Although Tom came to the consulting session for statistical assistance, this statistical information seemed secondary to his own kinesiological knowledge.

Rhonda's session was focused more on statistical and methodological expertise, with little emphasis on disciplinary biology knowledge. She referred frequently to her limited statistical knowledge and spent most of the session asking Ian questions about statistics and methodology. She did not offer biological understandings as a context for any statistical or methodological decisions. One of the few biological concepts discussed in her session was the " $L D_{50}$ " (the lethal dose that kills $50 \%$ of a sample), which is a popular measure reported in various fields of biological research and is common knowledge to many biology students. Contrary to normal expectations, Ian introduced and defined $\mathrm{LD}_{50}$ rather than Rhonda. Ian had no training in biology, but had learned the importance of $\mathrm{LD}_{50}$ through years of consulting with biologists. In Rhonda's session, it seemed that Ian held the expertise in statistics and, to a lesser extent, even in biology.

For both Tom and Rhonda, expertise seemed to be uni-dimensional, leading to a focus on social mediation of individual learning for these clients (Salomon \& Perkins, 1998). Although cultural scaffolds were involved in this social mediation (as discussed below), the emphasis remained on what the individual clients learned, with little attention to any changing social dynamics or possible reciprocity in the learning situations.

Aaron's session, on the other hand, represented a distribution of expertise: Aaron saw himself as somewhat of an expert in his target species and was trying to learn more about statistics from Ian and the student consultants. Aaron's actions and questions acknowledged multiple forms of expertise. He appeared genuinely interested in sharing his understandings of biology and biological research, and in finding out all he could about statistics and statistical consulting. He patiently explained the reproduction cycle of his target species and the infesting parasite when questioned by the student consultant. At the same time, Aaron asked questions about recommended statistical techniques and design issues relevant to his study. He discussed the proposed suggestions and related them to information he already knew and techniques he had tried. As well, Aaron expressed interest in a range of topics (statistics, insect biology, postgraduate education, employment prospects) and, through his comments and questions, acknowledged that he could learn from various sources. This perspective is aligned with Salomon and Perkins' (1998) description of social mediation through participatory knowledge construction. Together, Aaron and the other members of the consulting session (Ian, Diane, and me) constructed understandings about research conducted in the lab where Aaron worked.

At the same time, Aaron's interest in improving conditions for other postgraduate students in his lab seemed to fit with Salomon and Perkins' (1998) notion of the social entity as a learning system. Aaron intended to share what he learned in the consulting session with other members of his lab, so all lab members could benefit from the session and work together to convince his supervisor and their department to support the work of the statistical consulting centre. The consulting session was aimed at increasing knowledge for his entire lab, not just for Aaron individually.

Across the three examples, it is clear that statistical consulting requires a mix of statistical and disciplinary expertise; however, the three examples illustrate differences in relative emphasis on the two types of expertise. Tom's session emphasized disciplinary expertise, Rhonda's session emphasized statistical expertise, and Aaron's session provided a closer balance between disciplinary and statistical expertise. The three examples also differ in terms of the locus (internal or external) of expertise. Tom emphasized his own internal expertise, Rhonda emphasized external expertise from Ian, and Aaron emphasized both internal and external forms of expertise. Finally, the 
examples point to differences in the number of sources of expertise that were considered relevant. Rhonda's session focused on Ian's expertise, Tom's session focused on Tom's and (to a lesser extent) Ian's expertise, and Aaron's session focused on all participants as sources of expertise. Figure 1 is a heuristic representation of these three dimensions of expertise (type, locus, and source). Notice that in these sessions the first two dimensions (type and locus) reflect a similar pattern even though not all three sessions reflected the typical attribution of disciplinary knowledge to clients and statistical knowledge to consultants (Belli, 2001).

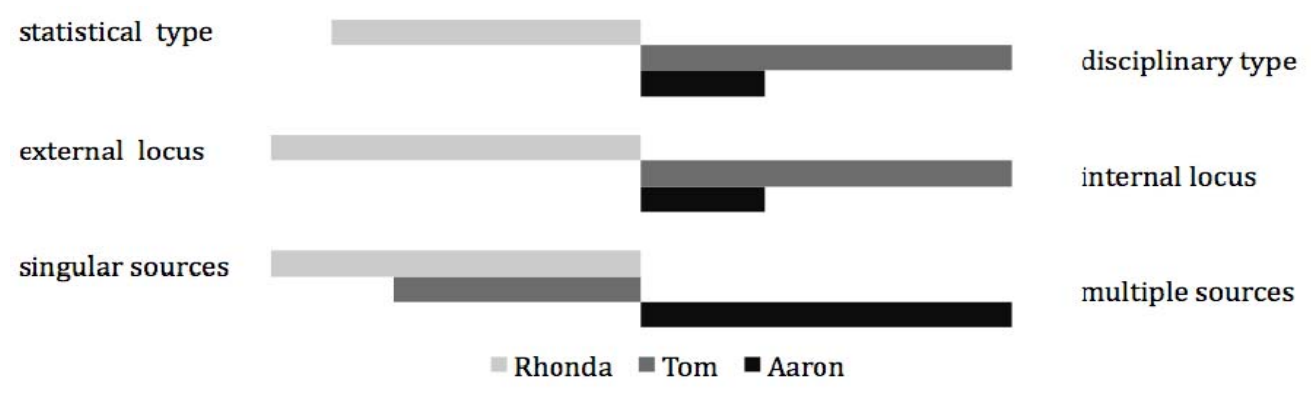

Figure 1. Heuristic representation of the type, locus, and source of expertise emphasized in different consulting sessions

Regardless of the locus or source of expertise, the consulting sessions necessarily involved a mix of statistical and disciplinary expertise (Belli, 2001). In a university-based statistical consulting centre where consultants assist clients to do their own statistical analyses, a strong emphasis on disciplinary expertise makes sense as the focus tends to be on choosing and implementing statistical techniques to support discipline-based goals and communication. In such situations, consultants can share statistical expertise to complement clients' disciplinary expertise. This expected relationship was not evident for Rhonda who presented as a neophyte and deferred to Ian on both statistical and disciplinary grounds and, in that way, her session seemed similar to sessions where consultants conduct statistical analyses for clients.

\subsection{THE ROLE OF MATERIAL OBJECTS AND REPRESENTATIONS}

Consultants and clients influenced the activities and conversations in the consulting sessions, thereby affecting the associated learning. Likewise, material objects and representations served as cultural scaffolds that mediated activities, conversations, and associated learning (Latour, 1987; Salomon \& Perkins, 1998).

Material objects provided focal points for the conversations and served as visual illustrations to support verbal claims and questions. For example, Aaron's cage was a physical representation of his study design. He was testing the efficacy of five different doses of 16 possible treatments intended to kill infesting parasites without harming the target species. In his research, he had multiple cages to test each comparison to ensure an adequate sample size. The sample cage he brought allowed him to explain and justify his study design. We could see that the parasites were tiny and camouflaged by the colours of the target species, allowing us to confirm that Aaron needed statistical analyses that did not require a controlled number of parasites. The cage also provided backup support when Aaron described the life cycle of the parasites and the impossibility of reproduction within the cage. The cage was an important material object that assisted sense making. 
Beyond material objects, written representations also played central roles in the consulting sessions. Statistical output, pages from software manuals, schematic diagrams, and handwritten notes created before and during sessions contributed to our conversations and thinking. Ian, the student consultants, the clients, and I all made notes. Sometimes these notes were for individual consumption (e.g., my fieldnotes), but more frequently these notes were shared with other participants to clarify questions and answers. For example, as Ian presented the mini-lesson on degrees of freedom for Rhonda, he and one of the student consultants (Wendy) collaboratively produced a record of their calculations (see Figure 2). Upon completion of this record, Ian concluded that Rhonda had sufficient degrees of freedom to analyze all two-way interactions among the main factors in her study (dose, time, species), but that there were insufficient degrees of freedom to analyze the three-way interaction. Ian's conclusion came without computing the additional degrees of freedom required to analyze the three-way interaction $(4 \times 3 \times 2=24)$ or relating this amount to the total degrees of freedom available $(60-1=59)$. It was sufficient for Ian to note that $9+26<59$ and therefore acceptable. Ian provided further justification for his conclusion by noting that "three-way interactions are difficult to interpret anyway." The notes in Figure 2 were written on a sheet of paper that became a lasting record that Rhonda took away with her to reference as she performed the calculations and wrote her thesis.

$\begin{array}{lll}\mathrm{df}=60 & -1 \mathrm{for} \text { estimating overall mean } & \begin{array}{l}\text { dose } \times \text { time } \\ \text { species } \times \text { time }\end{array} \\ \text { dose } 4 & 3 \mathrm{df} & \begin{array}{l}4=6 \\ \text { dose } \times \text { species }\end{array} \\ \text { time } 3 & 2 \mathrm{df}=12 & \\ \text { species } 5 & \underline{4 \mathrm{df}} & \end{array}$

Figure 2. Notes from a mini-lesson on degrees of freedom

Clients also created visual representations to clarify their understandings and the questions that they wanted to ask. For example, when Aaron talked about the expected differences between the death rates of his target species and the infesting parasites, he sketched the two distributions presented in Figure 3. He wanted to find out the optimum dose that would kill parasites without harming his target species, so he wanted to maximize the difference in death rates for the two species (the peak in Figure 3b). The second sketch illustrated that Aaron expected the differences in death rates to be normally distributed and therefore amenable to parametric statistical procedures. Consistent with published research (Henderson, 1999; Roth \& McGinn, 1998), these sketches made our conversations possible because they allowed us to focus on specific information and facilitated our conversations through indexical language (e.g., "here," "this," "at this
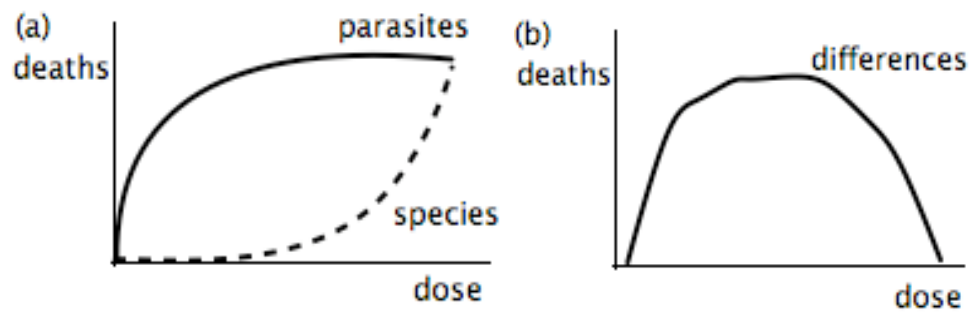

Figure 3. Aaron's sketches of death rates for his target species and the infesting parasite 
point”). The sketches also prompted Aaron to shift his strategy for graphs in his thesis. Prior to the consulting session, Aaron had graphed death rates separately for the target species and parasites, yet he realized that he could illustrate the death rates more effectively by superimposing the graphs on one set of axes, as he did in his spontaneous sketches during the consulting session (see Figure 3a).

There were also instances where visual representations constrained understandings. The most telling example occurred in Tom's consulting session. Tom began his session by sketching measures of muscle activity (the dependent variables in his study) as eight vectors that could be arranged in the shape of an octagon as depicted in Figure 4a. After sketching the octagon, Tom described his need to document changes in the shape and orientation of such octagons to assess the outcomes of his study. Ian's first response was that mathematical or graph theoretic approaches rather than statistical approaches would be required and he began brainstorming names of colleagues who might be able to assist. The visual depiction prompted a focus on dimensions that were difficult to capture with standard statistical techniques. We promptly rejected strategies involving measuring area, fitting a curve, or measuring concavity or convexity for none of these options could fully capture changes in the shape of such octagons.

(a)

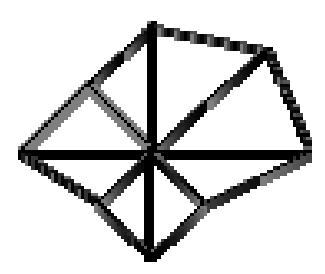

(b)

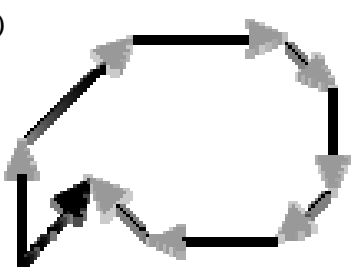

Figure 4. (a) Tom's sketch of an octagon representing 8 related outcome measures and

(b) a translation of the 8 outcome measures into individual vectors with the corresponding vector sum represented by the dark arrow

After considerable discussion, we returned to the original idea that the octagon was created from normalized vectors and, through Mirjana's attempted intervention, Tom concluded that vector-sum comparisons would lead to an appropriate analysis for his study. The black arrow in the vector-sum diagram (Figure 4b) visually depicts the vector sum of the 8 vectors used to create the octagon in Figure 4a. This vector-sum diagram was not sketched in the consulting session, but is presented here to show the shift in interpretation. The vector sum contains all of the measurement information from Tom's octagon, but no reference to the octagon's physical shape, which had been distracting because it did not correspond to actual measures of muscle activity.

These examples highlight the multiple ways that material objects and representations influenced practices and learning during consultations. The range of material objects and representations showed that consultants and clients were not limited to the simple graphs that Boen and Zahn (1982) suggested as useful components in statistical consulting, thereby extending the information typically found in statistical consulting handbooks. 


\section{THEORETICAL AND PRACTICAL IMPLICATIONS OF THE CASE STUDY}

Consistent with published literature (Belli, 2001; Godino et al., 2001), the statistical consulting centre provided a learning space for clients and consultants. The clients learned techniques or approaches to address challenges in their research. The student consultants learned consulting skills, along with some knowledge from the different disciplines and an increased level of confidence to engage in consulting. Ian continued to develop as a consultant and a supervisor of student consultants. Learning was accomplished in the social context of the consulting centre where clients and consultants met to discuss issues related to using statistics in research.

The three selected consultations illustrate all five forms of social learning (Salomon \& Perkins, 1998) evident throughout the fieldwork. Active social mediation of individual learning dominated for Rhonda and Tom, whereas participatory knowledge construction was prevalent for Aaron. All three sessions included material objects and representations that served as cultural scaffolds for learning. There was also direct and indirect evidence of social entities acting as learning systems: Ian and the student consultants formed a consulting team that developed over time, and Aaron emphasized his lab group's collective learning. Throughout, consultants and clients demonstrated skills as social learners that allowed them to communicate successfully with each other. These five forms of social learning reflect the three key themes related to types of clients and consulting interactions, disciplinary and statistical expertise, and material representations.

Differences in the ways that clients presented themselves, their research, and their questions suggested differences in the kinds of identities that those clients had constructed for themselves in consulting. Rhonda presented herself as a neophyte in statistics and even in biology. Her interactions placed her in a subordinate position to Ian and her supervisor (Vezina, 1998). In contrast, Aaron presented himself and his work in a self-confident and professional manner, thereby constructing an identity as a biologist and a colleague to those in the consulting session. Tom, the academic staff member, clearly took control and presented himself as a kinesiologist. Differences in clients' selfpresentation styles prompted Ian to respond variably as counsellor, colleague, or technician. Clients and consultants perform their roles differently, based upon their understandings of themselves as social learners. Consultants must be attuned to the particular needs and feelings projected by clients and recognize that no single approach works for all consultations (Derr, 2000; Platt, 1982). Through their internships, the student consultants were learning to be social learners who could adapt their styles or roles as Ian did.

It was also evident that expertise was distributed differentially across the consulting sessions. There was variability in the type, locus, and sources of expertise that predominated in the different sessions. Consultants and clients alike needed to draw upon statistical, computational, methodological, disciplinary, and social practices. In university-based consulting sessions, there is typically a distribution of expertise whereby the consultant has statistical knowledge and the client has disciplinary knowledge; however, both parties need to understand enough about statistics and the discipline to be able to communicate. When the two sources of expertise are brought together, there are opportunities for consultants and clients to contribute to and learn from the session. As Boen and Zahn (1982) argue, "to be effective, the consultant must use statistical expertise in collaboration with disciplinary expertise of the client” (p. 25). Furthermore, clients must use their disciplinary expertise in collaboration with consultants' statistical expertise. The give and take between statistical and disciplinary knowledge was evident in Tom's and Aaron's sessions, but the emphasis in the two sessions was different due to 
Tom's individual, disciplinary focus compared to Aaron's participatory, balanced focus. In contrast, Ian provided both statistical and disciplinary knowledge in Rhonda's session; without his knowledge of biology, his statistical advice would have been of limited use for Rhonda. The specifics of a research setting as well as disciplinary interpretations of appropriate statistical analyses determine how an analyst should proceed. As Ian noted, it is acceptable to ignore three-way interactions in biological research and focus on the more easily interpreted main effects and two-way interactions. Such an approach might not work in another discipline, such as psychology where analysts would be expected to extend the sample size so that they could analyze the three-way interaction and conduct follow-up analyses to determine underlying effects. Consultants need to be attuned to disciplinary differences to provide appropriate advice. Consultants are typically called upon for their statistical knowledge, but disciplinary understandings are required to determine disciplinarily acceptable uses of statistical knowledge. Research and research reports are targeted toward a particular discipline, so statistical analyses need to be accepted by members of that target discipline. Tom, for example, referred to his plans to present his analysis in a journal manuscript for kinesiologists. The student clients focused on an intermediate audience within the university as they attended to the need to persuade their supervisory committee (Rhonda) or lab group (Aaron) of the appropriateness of their design and analysis decisions.

Material objects and representations influenced conversations, actions, and learning in the sessions. The selected examples highlight the multiple ways that these material resources served as cultural scaffolds (Salomon \& Perkins, 1998) that afforded particular practices or understandings and constrained others. Clients and consultants discussed the material objects and representations and benefited from the ways these objects embodied details that would have been cumbersome to explain verbally. The objects enabled gestures and indexical language (e.g., "here," "this," "these ones"). Sketches and notes became lasting records intended to guide future analyses and serve as templates for research reports. Whether the focus was participatory or individual learning, material objects and representations meditated possible learning for consultants and clients (Latour, 1987).

The mediating influence of people and objects affirms the contingent decision making involved in conducting statistical analyses. As with other ethnostatistical studies (Gephart, 1988, 2006), this case study revealed statistical analysis and statistical thinking as situated accomplishments. The process of engaging together in using statistics in research contributed to learning for consultants and clients (Belli, 2001; Godino et al., 2001). Textbooks provide information and procedures that can serve as guidelines in conducting statistical analyses, but textbooks cannot prespecify all that a statistician or researcher needs to consider. Textbook procedures inherently underspecify necessary actions (cf. Suchman, 1987). Practical considerations and the corresponding tacit understandings are best learned through practice not through textbook study (Roth, 2006). This is the notion that is at the heart of the authentic learning movement (Herrington \& Herrington, 2006; Rule, 2006). Textbooks can provide important cultural scaffolds for learning, but other social content can extend possibilities for learning.

The reciprocity of statistical consulting sessions as learning environments makes them ideal locations for investigating authentic learning. Consulting centres serve real needs within the university community; they provide assistance to members of the university community engaged in data-based research projects, and they provide a training ground for postgraduate students who may become professional consultants. Statistical consulting centres are authentic learning settings (Herrington \& Herrington, 2006; Rule, 2006). For consultants, consulting provides opportunities to apply statistical 
knowledge to discipline-based problems and to communicate about statistics. For clients, consulting provides opportunities to defend disciplinary commitments and to practice communicating statistically.

The internship was clearly educational for the student consultants. They had exposure to a range of clients and research problems, they were able to observe and model Ian's expert behaviour, and they had opportunities to debrief their experiences. The three selected consulting sessions presented here lasted approximately three hours, which is the minimal length of observation time required in the first term of the internship. After observing a series of consulting sessions like this, these postgraduate students were expected to participate actively as consultants in the second term. Given the diversity across clients, more time in the consulting service might be necessary to maximize learning and best prepare consultants for future independent practice.

The consulting sessions were also educational for student and staff clients. All clients left their consulting sessions with clear plans for implementing and reporting statistics in their research. With the support of Ian and the student consultants, the clients were prepared to undertake statistically sound research practices. Some disciplinary supervisors discourage students from using statistical consulting services because they believe students may not develop requisite proficiencies in statistics and research design. This case study shows that such fears are unwarranted. Postgraduate students are expected to undertake disciplined inquiry in their field and to be able to communicate the outcomes of their work. There was clear evidence that students learned and enacted disciplinary ways to use statistics. The consulting service provided advice and guidance, but clients were responsible for doing the work, justifying the decisions made, and communicating the results. Some students may require assistance in reaching this level, but this in no way undermines their fulfillment of degree expectations.

Effective interactions in statistical consulting require both statistical and disciplinary knowledge. Consulting is a learning experience for both consultants and clients (Belli, 2001), and it increases the methodological quality of research produced at an institution (Godino et al., 2001). In this way, a statistical consulting centre contributes positively to teaching and research for a university.

\section{ACKNOWLEDGMENTS}

This work was supported in part by the Social Sciences and Humanities Research Council of Canada. Earlier versions of this paper were presented at the Canadian Society for the Study of Education and the Society for Social Studies of Science conferences. Portions of the work have been adapted from my doctoral dissertation from Simon Fraser University (Burnaby, BC, Canada). The research would not have been possible without the generosity and openness of Ian, the student consultants, and the clients of the consulting service. Thank you as well to colleagues in the Faculty of Education Academic Writing Circle and to Ewelina Niemczyk for assistance with one of the figures.

\section{REFERENCES}

Belli, G. (2001). The teaching/learning process in university statistical consulting labs in the United States. In C. Batanero (Ed.), Training researchers in the use of statistics (pp. 325-338). Granada, Spain: International Association for Statistical Education and International Statistical Institute.

Boen, J. R., \& Zahn, D. A. (1982). The human side of statistical consulting. Belmont, CA: Lifetime Learning. 
Cabrera, J., \& McDougall, A. (2002). Statistical consulting. New York: Springer.

Charmaz, K. (2006). Constructing grounded theory: A practical guide through qualitative analysis (pp. 42-71). Thousand Oaks, CA: Sage.

Cohen, J. (1994). The earth is round ( $p<.05)$. American Psychologist, 49(12), 997-1003.

Creswell, J. W., \& Miller, D. L. (2000). Determining validity in qualitative inquiry. Theory Into Practice, 33, 124-130.

Derr, J. (2000). Statistical consulting: A guide to effective communication. Pacific Grove, CA: Duxbury Thomson Learning.

Dye, J. F., Schatz, I. M., Rosenburg, B. A., \& Coleman, S. T. (2000). Constant comparison method: A kaleidoscope of data. The Qualitative Report, 4(1/2). [Online: http://www.nova.edu/ssss/QR/QR4-1/dye.html ]

Emerson, R. M., Fretz, R. I., \& Shaw, L. L. (2001). Participant observation and fieldnotes. In P. Atkinson, A. Coffey, S. Delamont, J. Lofland, \& L. Lofland (Eds.), Handbook of ethnography (pp. 352-368). Thousand Oaks, CA: Sage.

Gephart, R. P., Jr. (1988). Ethnostatistics: Qualitative foundations for quantitative research. Newbury Park, CA: Sage.

Gephart, R. P., Jr. (Ed.). (2006). Ethnostatistics and organizational research methodologies: An introduction. Organizational Research Methods, 9(4), 417-431.

Godino, J. D., Batanero, C., \& Jaimez, R. G. (2001). The statistical consultancy workshop as a pedagogical tool. In C. Batanero (Ed.), Training researchers in the use of statistics (pp. 339-353). Granada, Spain: International Association for Statistical Education and International Statistical Institute.

Hand, D. J., \& Everitt, B. S. (Eds.). (2008). The statistical consultant in action. Cambridge, UK: Cambridge University Press.

Henderson, K. (1999). On line and on paper: Visual representations, visual culture, and computer graphics in design engineering. Boston, MA: MIT Press.

Herrington, A., \& Herrington, J. (2006). What is an authentic learning environment? In T. Herrington \& J. Herrington (Eds.), Authentic learning environments in higher education (pp. 1-13). Hershey, PA: Information Science Publishing.

Jersky, B. (2002). Statistical consulting with undergraduates-A community outreach approach. In B. Phillips (Ed.), Proceedings of the Sixth International Conference on Teaching Statistics: Developing a statistically literate society, Cape Town, South Africa. [CD-ROM]. Voorburg, The Netherlands: International Statistical Institute. [Online: http://www.stat.auckland.ac.nz/ iase/publications/1/3a1_jers.pdf ]

Jeske, D. R., Lesch, S. M., \& Deng, H. (2007). The merging of statistics education, consulting and research: A case study. Journal of Statistics Education, 15(3). [Online: http://www.amstat.org/publications/jse/v15n3/jeske.pdf ]

Latour, B. (1987). Science in action: How to follow scientists and engineers through society. Cambridge, MA: Harvard University Press.

Latour, B., \& Woolgar, S. (1986). Laboratory life: The construction of scientific facts. Princeton, NJ: Princeton University Press.

Lave, J., \& Wenger, E. (1991). Situated learning: Legitimate peripheral participation. Cambridge, UK: Cambridge University Press.

Lieberson, S. M. (1985). Making it count. Berkeley, CA: University of California Press.

Lincoln, Y. S., \& Guba, E. G. (1985). Naturalistic inquiry. Newbury Park, CA: Sage.

Lynch, M. E. (1985). Art and artifact in laboratory science. London, UK: Routledge \& Kegan Paul.

McCloskey, D. N. (1985). The rhetoric of economics. Madison, WI: University of Wisconsin Press. 
McGinn, M. K. (2009). Socially distributed knowledge. In A. J. Mills, G. Durepos, \& E. Wiebe (Eds.), Encyclopedia of case study research (pp. 879-882). Thousand Oaks, CA: Sage.

Merriam, S. B. (2009). Qualitative research: A guide to design and implementation (2 ${ }^{\text {nd }}$ ed.). San Francisco: Wiley.

Onwuegbuzie, A. J. (2000). Statistics anxiety and the role of self-perceptions. Journal of Educational Research, 93(5), 323-330.

Packer, M. J., \& Goicoechea, J. (2000). Sociocultural and constructivist theories of learning: Ontology, not just epistemology. Educational Psychologist, 35(4), 227-241.

Patton, M. Q. (1980). Qualitative evaluation methods. Newbury Park, CA: Sage.

Platt, R. D. (1982). Client-consultant interaction. In J. S. Rustagi \& D. A. Wolfe (Eds.), Teaching of statistics and statistical consulting (pp. 503-509). New York: Academic Press.

Reid, A., \& Petocz, P. (2002). Students' conceptions of statistics: A phenomenographic study. Journal of Statistics Education, 10(2).

[Online: http://www.amstat.org/publications/jse/v10n2/reid.html ]

Roth, W.-M. (2006). Textbooks on qualitative research and method/methodology: Toward a praxis of method. Forum: Qualitative Social Research, 7(1), Art. 11.

[Online: http://www.qualitative-research.net/index.php/fqs/article/view/79/162 ]

Roth, W.-M., Bowen, G. M., \& McGinn, M. K. (1999). Differences in graph-related practices between high school biology textbooks and scientific ecology journals. Journal of Research in Science Teaching, 36(9), 977-1019.

Roth, W.-M., \& McGinn, M. K. (1998). Inscriptions: A social practice approach to "representations." Review of Educational Research, 68(1), 35-59.

Rule, A. C. (2006). The components of authentic learning. Journal of Authentic Learning, 3(1), 1-10.

Rustagi, J. S., \& Wolfe, D. A. (Eds.). (1982). Teaching of statistics and statistical consulting. New York: Academic Press.

Salomon, G., \& Perkins, D. N. (1998). Individual and social aspects of learning. Review of Research in Education, 23, 1-24.

Särkkä, A., \& Sagitov, S. (2008). Live case studies in a new course on statistical consulting.

[Online: http://www.math.chalmers.se/ serik/Papers/ailaserik.pdf ]

Stake, R. E. (2005). Qualitative case studies. In N. K. Denzin \& Y. S. Lincoln (Eds.), The Sage handbook of qualitative research ( $3^{\text {rd }}$ ed., pp. 443-466). Thousand Oaks: Sage.

Suchman, L. A. (1987). Plans and situated actions: The problem of human-machine communication. Cambridge, UK: Cambridge University Press.

Taplin, R. (2007). Enhancing statistical education by using role-plays of consultations. Journal of the Royal Statistical Society. Series A (Statistics in Society), 170(2), 267300.

Vezina, V. J. (1998). It's still a man's world: Women and graduate study. In J. Stalker \& S. Prentice (Eds.), The illusion of inclusion: Women in post-secondary education (pp. 72-84). Halifax, NS: Fernwood.

Wild, C. J., \& Pfannkuch, M. (1999). Statistical thinking in empirical enquiry. International Statistical Review, 67(3), 223-248.

MICHELLE K. MCGINN

Faculty of Education, Brock University 500 Glenridge Ave, St. Catharines ON

L2S 3A1 Canada 